\title{
Late Presentation of Idiopathic Tympanic Membrane Ossification with External Auditory Canal Stenosis
}

\author{
${ }^{1}$ Hitesh Verma, ${ }^{2}$ Arjun Dass, ${ }^{3}$ Surinder K Singhal, ${ }^{4}$ Nitin Gupta
}

\begin{abstract}
The external auditory canal (EAC) is formed by lateral cartilaginous and medial bony part. The stenosis of EAC is narrowing of the width of the EAC, i.e. either caused by congenital or acquired causes. Myringosclerosis is a condition caused by calcification of tissues in the tympanic membrane and ossification is a special form of fibrosis due to the long-term, irreversible continued inflammation in the middle ear cleft. We are presenting rare case of idiopathic tympanic membrane ossification with generalized stenosis of EAC in 29-year-old patient.
\end{abstract}

Keywords: External auditory canal, Ossification, Stenosis, Tympanic membrane.

How to cite this article: Verma H, Dass A, Singhal SK, Gupta N. Late Presentation of Idiopathic Tympanic Membrane Ossification with External Auditory Canal Stenosis. Int J Otorhinolaryngol Clin 2015;7(3):141-143.

Source of support: Nil

Conflict of interest: None

\section{INTRODUCTION}

The external auditory canal (EAC) is formed by lateral cartilaginous and medial bony part. At 26 to 28 weeks of gestation, the lateral soft tissue portion of the EAC develops by canalization of epithelial plug derived from first branchial cleft. The bony component changes from half of the length of the tubular EAC in children to two-thirds of the length of the tubular EAC in adults. The failure of canalization of epithelial plug formed from first branchial arch lead to congenital atresia of the EAC. The stenosis of EAC is narrowing of the width of the external auditory canal, i.e. either caused by a congenital malformation ${ }^{1}$ or is acquired, secondary to

\footnotetext{
${ }^{1,4}$ Assistant Professor, ${ }^{2}$ Professor and Head

${ }^{3}$ Associate Professor

${ }^{1}$ Department of Otorhinolarygology and Head and Neck Surgery All India Institute of Medical Sciences, New Delhi, India

${ }^{2-4}$ Department of Otorhinolaryngology and Head and Neck Surgery, Government Medical College and Hospital, Chandigarh India

Corresponding Author: Hitesh Verma, Assistant Professor Department of Otorhinolaryngology and Head and Neck Surgery, All India Institute of Medical Sciences, New Delhi, India Phone: 9417129709, e-mail: hitesh_verma72@yahoo.com
}

persistent otitis externa, trauma (surgical or non-surgical), malignancy or irradiation. ${ }^{2}$ These acquired causes produce stenosis by inducing thickening of the subcutaneous tissue. Myringosclerosis is a condition caused by calcification of tissues in the tympanic membrane and ossification is a special form of fibrosis due to the long-term, irreversible continued inflammation in the middle ear cleft. ${ }^{3,4}$

We are presenting rare case of idiopathic tympanic membrane ossification with generalized stenosis of EAC in 29-year old patient.

\section{CASE REPORT}

A 29-year-old male patient presented with history of progressively decrease in hearing from left ear for 6 months. There was no history of discharge from ear, tinnitus, vertigo. He also has no history of prior trauma, ear surgery and systemic illness. The family history was not contributory. Local examination showed narrowing of EAC in complete length, which was started from outer limit (Fig. 1). The anterior part of tympanic membrane was seen through EAC. The high resolution computed tomography (HRCT) scan of temporal bone revealed generalized narrowing of left EAC $(5.5 \times 5.1 \mathrm{~mm})$ with scutum extended inferiorly till the tip of handle of malleus as compare to right side $(7.5 \times 7.1 \mathrm{~mm})$ (Fig. 2). The rest of middle ear cleft and inner ear with facial nerve canal was normal on both sides. The pure tone audiometry showed conductive hearing loss (15/80). The

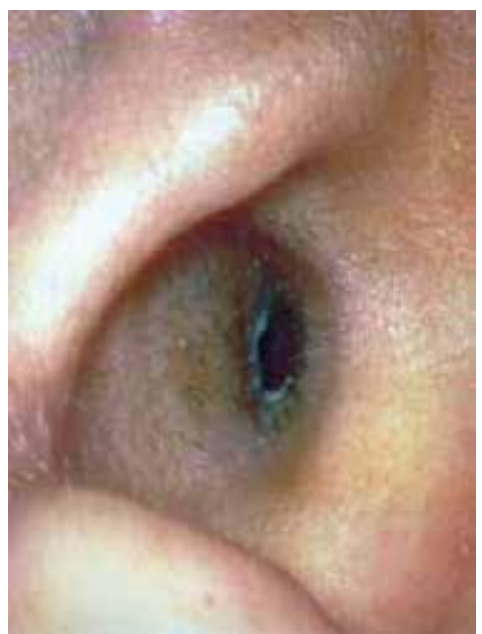

Fig. 1: Narrowing started from beginning of external auditory canal 


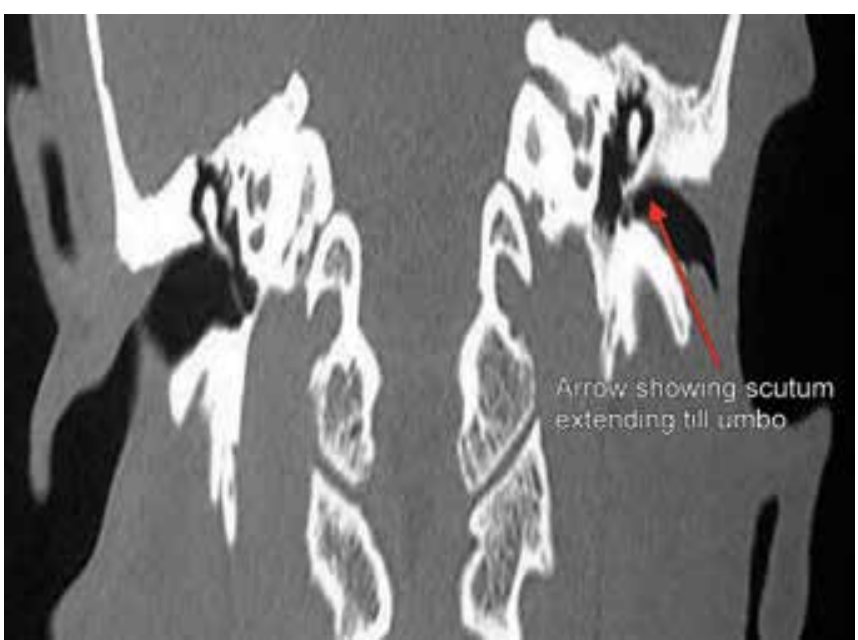

Fig. 2: High resolution computed tomography temporal bone coronal view showing narrowing of external auditory canal in bony and cartilaginous part left side with extension of scutum till umbo of tympanic membrane (red arrow)

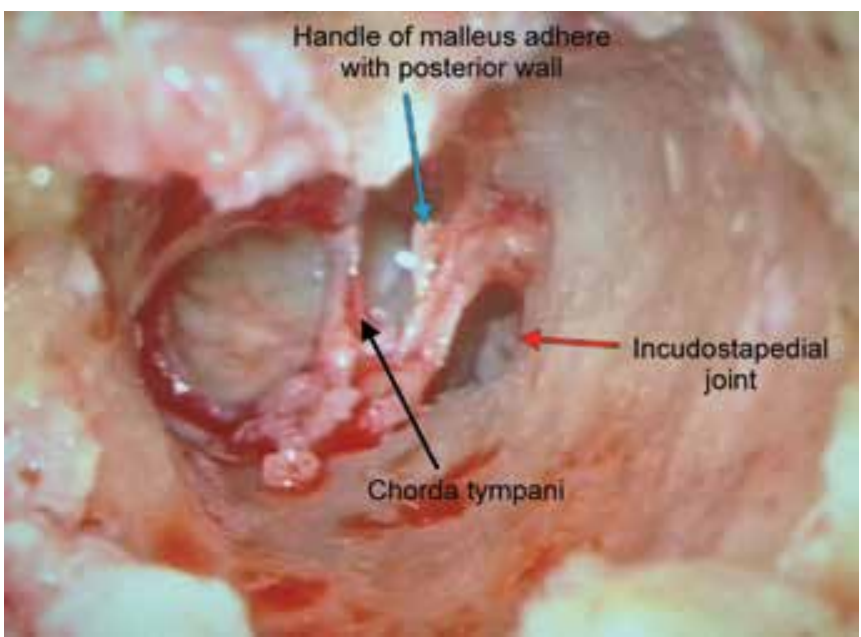

Fig. 4: Chorda tympani (black arrow) running below handle of malleus (blue arrow)

meatoplasty by post-auricular approach was done with preservation of canal skin. There was generalized stenosis of cartilaginous and bony part of EAC with ossification of posterior half of tympanic membrane with handle of malleus in it. The incudostapedial (IS) joint with normal mobility was seen through small defect between ossified tympanic membrane and medial limit of EAC (Fig. 3). The tip of handle of malleus found attached with posterior wall of EAC after drilling of ossified tympanic membrane through small defect. The ossicular mobility started after removal of attached part with malleus head nipper. The Chorda tympani was running below tip of handle of malleus (Fig. 4). The wide conchoplasty was done. The large temporal fascia graft used to prepare neotympanum and to cover bony part of EAC with thinned out tympanomeatal flap. The ear pop placed in EAC and wound closed in layers. The patient called every week for 6 weeks to examine progress of healing (Fig. 5). The postoperative pure tone audiogram showed hearing improvement.

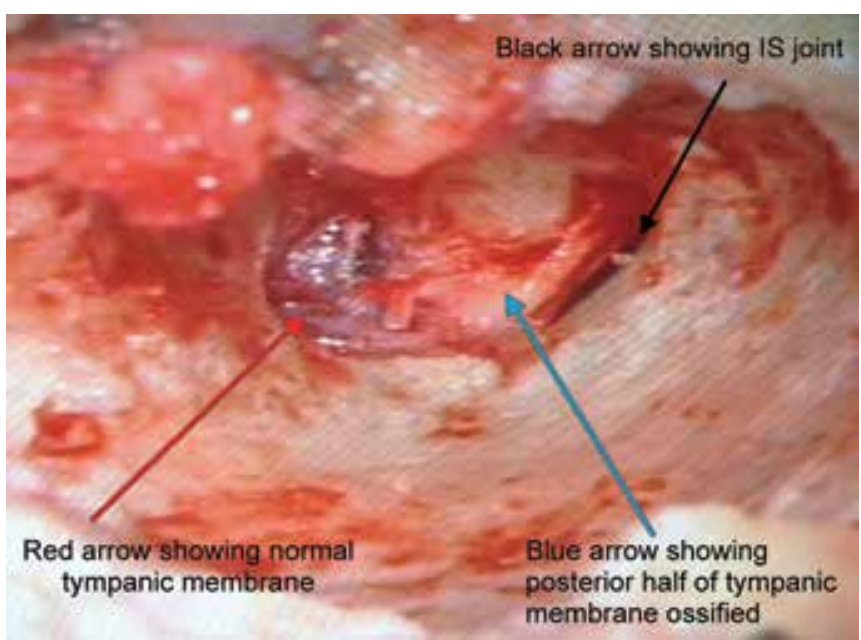

Fig. 3: Posterior half of tympanic membrane ossified (blue arrow) with IS joint viewed through narrow slip (black arrow)

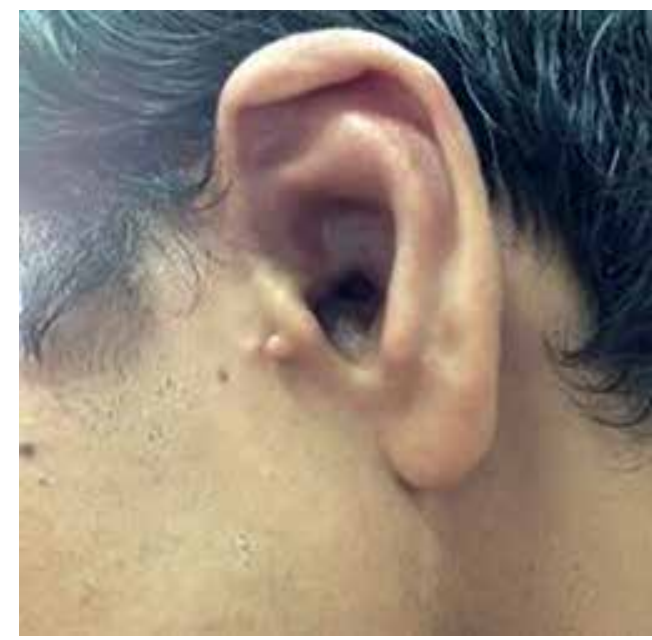

Fig. 5: Postoperative view showed wide external auditory canal

\section{DISCUSSION}

External auditory canal extends from pinna till the tympanic membrane. Acquired stenosis of external auditory canal caused by different factors which leads to canal fibrosis whereas no cause found in our case. The causative factors for myringosclerosis are long standing otitis media ${ }^{4}$ and insertion of a tympanostomy tube ${ }^{5-7}$ opposite to our case. Pathologically, tympanosclerosis is the final outcome of healing process in which the hyalinization of collagen in fibrous tissue and becomes fused into a homogeneous mass. Deposits of calcium salts, appearing as basophilic dust-like areas, are irregularly distributed through the collagen and calcification and even ossification can occur to a variable extent. Uniform and complete ossification of tympanic membrane raised the possibility of bony overgrowth from annulus. ${ }^{8}$

The most common presentation in patients with EAC stenosis and tympanic membrane sclerosis is hearing 
loss. ${ }^{5}$ The presence of canal stenosis causes associated morbidity, such as chronic discharge which is difficult to treat medically.

The investigation battery includes audiogram and HRCT temporal bone. The audiogram indicated for degree, type of hearing loss and for documentation purpose. High resolution computed tomography temporal bone review focuses on external-ear, middleear, and inner-ear development, on the boundaries and relationship with surrounding structures.

Symptomatic ossification of tympanic membrane and narrowing of external auditory canal, surgery is the primary treatment. ${ }^{9}$ The goal of surgery is simply to establish mobile tympanic membrane and open external auditory canal, which may require addressing the tympanic membrane with cartilaginous or bony portions of the EAC. ${ }^{10}$ The aim of surgery is to reconstruct normal tympanic membrane with dry, patent ear canal by enlarging the bony canal and cartilaginous meatus and by excising the thickened subcutaneous tissue. To line the external auditory canal various transposition flaps, rotation flaps, split thickness and full thickness skin grafts are proposed in different studies. ${ }^{11-16}$

Recent studies have demonstrated that a meatoplasty alone is sufficient to treat canal stenosis as in our case. ${ }^{1,17}$ By enlarging width of canal and removal of thickened tissue, the condition of the ear is stable. This would suggest that the normal function of the ear is restored, enabling a normal ear cleansing cycle and preventing the vicious cycle.

\section{REFERENCES}

1. Lavy J, Fagan P. Canaloplasty: review of 100 cases. J Laryngol Otol 2001 Apr;115(4):270-273.

2. Carls JL, Mendenhall WM, Morris CG, Antonelli PJ. External auditory canal stenosis after radiation therapy. Laryngoscope 2002 Nov;112(11):1975-1978.

3. Forseni M, Bagger-Sjoback D, Hultcrantz M. A study of inflammatory mediators in the human tympanosclerotic middle ear. Arch Otolaryngol Head Neck Surg 2001;127(5): 559-564.

4. Asiri S, Hasham A, al Anazy F, Zakzouk S, Banjar A. Tympanosclerosis: review of literature and incidence among patients with middle-ear infection. J Laryngol Otol 1999; 113(12):1076-1078

5. Isaacson JE, Vora NM. Differential diagnosis and treatment of hearing loss. Am Family Physic 2003;68(6): $1125-1132$.

6. Kay DJ, Nelson M, Rosenfeld RM. Meta-analysis of tympanostomy tube sequelae. Otolaryngology Head Neck Surg 2001;124(4):374-380.

7. Johnston LC, Feldman HM, Paradise JL, et al. Tympanic membrane abnormalities and hearing levels at the ages of 5 and 6 years in relation to persistent otitis media and tympanostomy tube insertion in the first 3 years of life: a prospective study incorporating a randomized clinical trial. Pediatrics 2004;114(1):58-67.

8. Baer S, Hehar S, Maw AR. Tympanic membrane ossification. J Laryngol Otol 1993 Jun;107(6):550-552.

9. Luong A, Roland PS. Acquired external auditory canal stenosis: assessment and management. Curr Opin Otolaryngol Head Neck Surg 2005;13(5):273-276.

10. Jacobsen N, Mills R. Management of stenosis and acquired atresia of the external auditory meatus. J Laryngol Otol 2006 Apr;120(4):266-271.

11. Soliman T, Fatt-Hi A, Kadir AM. A simplified technique for the management of acquired stenosis of the external auditory canal. J Laryngol Otol 1980 May;94(5):549-552.

12. Adkins WY, Osguthorpe JD. Management of canal stenosis with a transposition flap. Laryngoscope 1981 Aug;91(8): 1267-1269.

13. Moore GF, Moore IJ, Yonkers JA, Nissen AJ. Use of full thickness skin grafts in canal plasty. Laryngoscope 1984 Aug;94(8):1117-1118.

14. McDonald TJ, Facer GW, Clark JL. Surgical treatment of stenosis of the external auditory canal. Laryngoscope 1986 Aug;96(8):830-833.

15. McCary WS, Kryzer TC, Lambert PR. Application of splitthickness skin grafts for acquired diseases of the external auditory canal. Am J Otol 1995 Nov;16(6):801-805.

16. Bell DR. External auditory canal stenosis and atresia: dual flap surgery. J Otolaryngol 1988 Feb;17(1):19-21.

17. Fisch U, Chang P, Linder T. Meatoplasty for lateral stenosis of the external auditory canal. Laryngoscope 2002 Jul;112 (7 Pt 1):1310-1314. 